\title{
Anti-AXL/PBD Antibody-drug Conjugate ADCT-601
}

National Cancer Institute

\section{Source}

National Cancer Institute. Anti-AXL/PBD Antibody-drug Conjugate ADCT-601. NCI

Thesaurus. Code C160890.

An antibody-drug conjugate (ADC), consisting of a humanized immunoglobulin (Ig) G1 monoclonal antibody directed against AXL receptor tyrosine kinase ( $A X L ; U F O$ ) that is sitespecifically conjugated to PL1601, which contains a valine-alanine cleavable linker and SG3199, a cytotoxic pyrrolobenzodiazepine (PBD) dimer, with potential antineoplastic activity. Upon administration, the monoclonal antibody moiety of anti-AXL/PBD antibodydrug conjug ate ADCT-60 binds to AXL, which is expressed on the surfaces of a variety of cancer cell types. Upon endocytosis and enzymatic cleavage, free PBD is released and forms highly cytotoxic DNA interstrand cross-links, thereby blocking cell division and killing AXL-expressing cancer cells. AXL, a member of the TAM (TYRO3, AXL and MER) family of receptor tyrosine kinases, is overexpressed by many tumor cell types, and plays a key role in tumor cell proliferation, survival, invasion and metastasis; its expression is associated with drug resistance and poor prognosis. 